\title{
SIMULTANEOUS DETERMINATION OF ANTIBIOTIC RESIDUES (ENROFLOXACIN, CIPROFLOXACIN, DOXYCYCLINE AND CHLORAMPHENICOL) IN MILK OF JORDAN MARKET
}

\author{
HASAN Y. MUTI ${ }^{*}$, DIMA F. KHATER ${ }^{2}$, AHMAD M. KHALAF $^{3}$, \\ AHMAD N. ABU-AWWAD ${ }^{4,5}$ and TAWFIQ A. ARAFAT ${ }^{5}$
}

'Faculty of Pharmacy, Al-Ahliyya Amman University, Amman 19328, Jordan

${ }^{2}$ Department of Chemistry, Faculty of Arts and Science,

Applied Science Private University, Amman 11931, Jordan

${ }^{3}$ Faculty of Allied Medical Sciences, Al-Ahliyya Amman University, Amman 19328, Jordan.

${ }^{4}$ Faculty of Pharmacy, Jerash University, Jerash 26150, Jordan

${ }_{5}^{5}$ Jordan Center for Pharmaceutical Research, Amman 11105, Jordan

\begin{abstract}
A new multi-residue analytical method for simultaneous determination of four antibiotic residues (doxycycline (DOX), enrofloxacin (EN), ciprofloxacin (CP) chloramphenicol (CAM) in cow's milk has developed and validated by liquid chromatography-tandem mass spectrometry, was successfully applied to investigate commercially available cow's milk in Jordan. The analytes including etoricoxib as IS were extracted using liquid-liquid extraction and separated from their matrix chromatographically by using Fortis UniverSil Cyano column $(50 \times 2.1 \mathrm{~mm}, 5 \mu \mathrm{m})$, eluted by a mobile phase of $0.5 \mathrm{mM}$ ammonium chloride /methanol /formic acid ( $35: 65: 0.08 \%, \mathrm{v} / \mathrm{v})$ and delivered isocratically at a constant flow rate of $0.4 \mathrm{~mL} / \mathrm{min}$ for total LC run time of $1 \mathrm{~min}$. Twenty-six cow's milk samples from different brands of dry powder milk, long shelf-life milk, and raw untreated milk were collected randomly from the Jordanian market and analyzed in the triplicate analysis. The calibration curve was linear within the dynamic range of $10-1000 \mathrm{ng} / \mathrm{mL}$ in spiked milk for each analyte and the correlation coefficients were greater than 0.9973 for all calibration curves during validation. The internal standard-normalized matrix effects extend from 0.901 to 1.11 . The intra-assay and inter-assay precision normalized matrix effects extend from 0.901 to 1.11. The within-day and between-day precision ranged from $2.60-12.71 \%$ and $2.68-12.66 \%$, respectively, and the relative error of accuracy does not exceed $15 \%$. The results obtained are less than the approved stated regulatory guidelines and all samples screened were found to be free of any of the antibiotics tested.
\end{abstract}

Keywords: antibiotic residues, milk, LC-MS/MS

\begin{abstract}
Abbreviations: (MRL) Maximum Residue Limit, (EN) Enrofloxacin, (CI) Ciprofloxacin, (DOX) Doxycicline, (CAM) Chloramphenicol, (ADI) Acceptable Daily Intake, (LLOQ) Lower Limit of Quantitation, (IS) Internal Standard, (CV) Coefficient of variation, (LLOQ) Lower Limit of Detection Quantity, (BLOQ) Below Limit of Quantitation.

Antibiotics have widespread use in the veterinary and agriculture sector, besides their significant use to treat infected food-producing animals. Some classes of antibiotics are added to the feed or of animals for growth promotion or for prophylaxis (1). Most farmers in developing countries including Jordan are misusing and or overusing antibiotics (2). Usually, farmers try to maximize their profits, using a lot of
\end{abstract}

antibiotics for a long time to protect and maintain the health of birds and animals, to avoid them from diseases, without knowing that these antibiotics and their residues have a negative and inappropriate effect on the health of society. Milk and other dairy products are susceptible to contamination by antibiotic residue.

Inappropriate administration of various antibiotics including fluoroquinolones, tetracyclines, and amphenicols causes adverse health effects such as allergies (e.g. penicillin), and cancer induction (e.g., sulphamethazine) (3). Adding to that, non-prudent use of antibiotics is the reason for the development of antibiotic-resistant strains that makes antibiotics ineffective as therapeutic agents (4). Moreover, the broad-spectrum antibiotics contribute to the disturbance of various gastrointestinal microbiota because

* Corresponding author: e-mail: hasanymuti@gmail.com 
they attack and kill a wide range of intestinal flora and benign bacteria (5).

International organizations such as the European Commission (EC), World Health Organization (WHO), Food and Agricultural Organization (FAO), and United States Food and Drug Administration (USFDA) authorize limits on the residue levels of antibiotic drugs that are permitted in animal-derived food to protect consumers (6-7). Maximum residue levels (MRLs) and the acceptable daily intake (ADI) are established after performing toxicological analysis and pharmacokinetics studies. Table 1 shows some accepted MRLs values for residues of veterinary drugs in milk established by which international organization such as EC, WHO and FAO (8-9).

Table 1. Maximum Residue Limits (MRLs) for residues of veterinary drugs in milk.

\begin{tabular}{|c|c|}
\hline Antibiotics & MRL $(\mu \mathrm{g} / \mathrm{kg}$ body weight $)$ \\
\hline Enrofloxacin & 100 \\
\hline Ciprofloxacin & 100 \\
\hline Doxycycline & 3 \\
\hline Chloramphenicol & Should not be detected \\
\hline
\end{tabular}

Huge numbers of veterinary drugs containing fluoroquinolones had been introduced into the market by the end of the 1980s and beginning of the 1990s, due to their low toxicity and large antimicrobial spectrum. Fluoroquinolones cause cytostasis and cell death for bacteria or tumors by acting as DNA gyrase and DNA topoisomerase inhibitors (10). Enrofloxacin (EN)

a)<smiles>O=C(O)c1cn(C2CC2)c2cc(N3CCNCC3)c(F)cc2c1=O</smiles>

c)<smiles>Cc1cccc2c1C(=O)C1=C(O)[C@]3(O)C(=O)C(C(N)=O)=C(O)[C@H](N(C)C)[C@@]3([C@H]2C)[C@H](O)[C@H]1C</smiles>

-a quinolinemono carboxylic acid that is 1,4-dihydroquinoline-3-carboxylic acid)- (Figure 1a), and ciprofloxacin (CP) -1-cyclopropyl-6-fluoro-4-oxo-7-piperazin-1-ylquinoline-3-carboxylic acid; - (Figure 1b) are the most widely used fluoroquinolones for veterinary use. Doxycycline (DOX) -4S, 4aR, 5S, 5aR, 6R, 12aS)4-(Dimethylamino)-3,5,10,12,12a-pentahydroxy6-methyl-1,11-dioxo-1,4,4a, 5,5a,6,11,12a-octahydrotetracene-2-carboxamide - (Figure 1c), that belongs to the tetracycline class and chloramphenicol (CAM) -2 , 2-dichloro-N-[(1R, 2R)-1, 3-dihydroxy-1-(4-nitrophenyl) propan-2-yl] acetamide - (Figure 1d) are recognized as a broad-spectrum antibiotic which have high potency to prevent or cure infections caused by bacteria or some specific parasites for both humans and animals (11).

In order to determine the number of antibiotic residues in different forms of food including milk, several analytical methods have been developed utilizing liquid chromatography-tandem mass spectrometry (LC-MS/MS). Most of the reported LC-MS/MS analysis methods have a drawback of long analysis time (12) and are too expensive (using solid-phase extraction procedure) (13). Some studies using extraction methods including protein direct precipitation step by methanol $(14,15)$. Other reported methods require acetonitrile usage, and this causes the MS detection system susceptible to contamination. $(12,16,17)$.

Although there are tremendous studies on the analysis of antibiotic residues in milk, none has yet described a fast and throughput method for the simultaneous determination of enrofloxacin, doxycycline, ciprofloxacin, and chloramphenicol in a single b)<smiles>CCN1CCN(c2cc3c(cc2F)c(=O)c(C(=O)O)cn3C2CC2)CC1</smiles>

d)<smiles>O=C(N[C@H](CO)C(O)c1ccc([N+](=O)[O-])cc1)C(Cl)Cl</smiles>

Figure 1a. Chemical structure of ciprofloxacin; Figure 1b. Chemical structure of enrofloxacin; Figure 1c. Chemical structure of doxycycline; Figure 1d. Chemical structure of chloramphenicol. 
run. The present study describes the development and validation of an easy and fast analytical method for simultaneous determination of four antibiotics residues (enrofloxacin, doxycycline, ciprofloxacin, and chloramphenicol) in milk. The overall aim was to obtain a fast and simple LC-MS/MS method with an inexpensive sample preparation protocol.

\section{EXPERIMENTAL}

\section{Materials}

Chloramphenicol palmitate (purity 99.6\%, working standard) was supplied by Mehta Api Private Limited (Mumbai, India). Ciprofloxacin hydrochloride (purity $>98 \%$, working standard) was purchased from Shangyu Jingxin (Shangyu, China). Enrofloxacin base (purity 99\%, working standard) was provided by Zhejiang Guobang Pharmaceutical (Zhejiang, China). Doxycycline Hyclate was purchased from Wuhan Lipharma Chemicals (Wuhan, China) and etoricoxib was supplied by Virdev Intermediates Pvt (Palsana, India). Methanol (chromatographic grade), tert- butyl methyl ether (TBME; chromatographic grade), acetic acid (Optima LC/MS grade), and formic acid (99.0\%; LCMS grade) were obtained from Fischer Scientific (Loughborough, USA). Blank milk for spiking of calibration and quality control samples was obtained from a green cow's farm in a rural region close to Ajloun city in Jordan.

\section{Instrumentation}

LC-MS/MS was used consisting of liquid chromatography (LC) Agilent 1200 series (USA) and an API 4000 mass spectrometer (AB Sciex, USA). The separation was performed on a $50 \mathrm{~mm} \times 2.1 \mathrm{~mm}$ column packed with $5 \mu \mathrm{m}$ particles (Fortis UniverSil Cyano; England). A mobile phase consisted of $35 \%$ of aqueous $0.5 \mathrm{mM}$ ammonium chloride, $0.08 \%$ formic acid and $65 \%$ methanol (v/v). The flow rate was $0.4 \mathrm{~mL} / \mathrm{min}$ and the total $\mathrm{LC}$ run time was $1 \mathrm{~min}$. The injected volume and injector temperature was $5 \mu \mathrm{L}$ and $10^{\circ} \mathrm{C}$, respectively. All analytes and the internal standard were detected on a mass spectrometer equipped with a Turbo ion spray ${ }^{\mathrm{TM}}$ interface at $500^{\circ} \mathrm{C}$ evaporation temperature. The operated ionization mode and detection mode was positive Electro-spray $(\mathrm{ESI}+)$ and multiple reaction monitoring $(\mathrm{MRM})$, respectively. The optimized precursor ions pairs were $\mathrm{m} / \mathrm{z} 445.1 \rightarrow 427.5$ for DOX, $360.4 \rightarrow 340.9$ for $\mathrm{EN}$, $332.2 \rightarrow 287.9$ for $\mathrm{CP}, 322.7 \rightarrow 274.9$ for CAM, and $359.0 \rightarrow 280.0$ for etoricoxib. The MS parameters were set as the following: Air (zero grade) as nebulizer and auxiliary gas, nitrogen (ultra-pure) as a curtain and collision gas, curtain gas pressure was $10 \mathrm{psi}$, collision gas pressure was $10 \mathrm{psi}$, ion spray voltage was $5500 \mathrm{~V}$, ion source gas one and ion source gas two were 25 and 45 psi, respectively and ion spray temperature was $500^{\circ} \mathrm{C}$. The computational analysis was done utilizing Analyst Software version 1.6.3.

\section{Sample collection}

Three forms of whole fat milk samples, including nine brands of powdered milk, fourteen brands of long-term milk, and three brands of untread raw milk, were collected from the Jordanian market and analyzed for the presence of antibiotics residues (CAM, EN, CP, and DOX).

The collected blank milk samples for spiking of calibrators and quality control samples were obtained from a green cow's farm in a rural region close to Ajloun city in Jordan. Furthermore, an antimicrobial activity screening test was conducted for long-life full-fat milk using seeded media with St. aureus gem +be bacteria.

\section{Preparation of stock and standard working solution}

Standard stock solutions of DOX, CAM, EN, and $\mathrm{CP}$ were prepared by weighing $10 \mathrm{mg}$ of each individual standard in a $10 \mathrm{~mL}$ volumetric flask and dissolving it in water: methanol mixture $(3: 7, \mathrm{v} / \mathrm{v})$ to obtain a final concentration of $1000 \mu \mathrm{g} / \mathrm{mL}$. A working mixed standard solution with a concentration of $25.0 \mu \mathrm{g} / \mathrm{mL}$ of DOX, CAM, EN, and CP was freshly prepared by transferring $250 \mu \mathrm{L}$ of the aliquots of the stock solution of each analyte into a $10 \mathrm{~mL}$ volumetric flask and making up to volume using a watermethanol mixture $(1: 1, \mathrm{v} / \mathrm{v})$.

Etoricoxib 2 microgram $/ \mathrm{mL}$ which was used as an internal standard was prepared using a watermethanol mixture $(1: 1 \mathrm{v} / \mathrm{v})$ as the diluent solvent.

\section{Calibration curves and quality control samples}

Blank milk samples were spiked with $50 \mu \mathrm{L}$ of IS ( $2.0 \mu \mathrm{g} / \mathrm{mL}$ etoricoxib). After that, the appropriate volume of working mixed standard solution or standard stock solutions of DOX, CAM, EN, and CP was added to the blank milk samples to get standard solutions. Standards solutions having concentrations equivalent to $10,20.50,100,300,600$, and $1000 \mathrm{ng} / \mathrm{mL}$ DOX, CAM, EN, and CP were obtained and used to plot calibration curves. Calibration curves were established by identifying the best fit of peak area ratios (peak - area analytes/ peak area internal standard) versus concentration and fitted to the equation $\mathrm{y}=\mathrm{mx}+\mathrm{b}$ by weighted least-squares regression $(1 / \mathrm{x})$.

Quality control (QC) samples were prepared at three concentration levels (low QC $=60 \mathrm{ng} / \mathrm{mL}$, me$\operatorname{dium} \mathrm{QC}=400 \mathrm{ng} / \mathrm{mL}$ and high $\mathrm{QC}=800 \mathrm{ng} / \mathrm{mL}$ ). 


\section{Extraction}

A $5 \mathrm{~mL}$ of solvent (dichloromethane- TBME, $15: 85, \mathrm{v} / \mathrm{v}$ ) was added to the $0.5 \mathrm{~mL}$ of milk spiked with $2.0 \mu \mathrm{g} / \mathrm{mL}$ of IS. Then, the milk was vortexed for $5 \mathrm{~min}$, centrifuged at $4400 \mathrm{rpm}$ at $5^{\circ} \mathrm{C}$ for $5 \mathrm{~min}$, and the organic layer was separated. Then, the organic layers were collected together and evaporated to dryness under dried ultra- pure compressed air at $40^{\circ} \mathrm{C}$. The residue was reconstituted with $250 \mu \mathrm{L}$ of methanol/ water/ acetic acid (70:30:0.1; v/v/v), vortexed for $1 \mathrm{~min}$, and kept in HPLC vials until analysis time. All milk samples were extracted and analyzed in triplicate.

\section{Bioanalytical method validations}

The method was validated for analyzing antibiotic residues in cow milk in concordance with the European guideline (18), taking into consideration the United States FDA guideline requirements (19). Both guidelines were considered as protocols for all validation sections. The validation was performed in order to evaluate the method in terms of specificity, sensitivity, calibration curve (linearity of response), accuracy, precision, matrix effect, and recovery.

\section{Specificity and selectivity}

The presence of endogenous interfering peaks was investigated by analyzing the extracted blank milk samples from eight different sources and compared to samples spiked with DOX, CAM, EN, and $\mathrm{CP}$ at the lower limit of quantitation (LLOQ; $10 \mathrm{ng} / \mathrm{mL}$ for DOX, CAM, EN, and CP). The interfering peak area should not exceed $20 \%$ of the peak area of the analyte and $5 \%$ of the peak area of the IS at the LLOQ $(18,19)$.

\section{Matrix effect}

The matrix effect for DOX, CAM, EN, and CP was investigated to assess the ion enhancement or suppression of each analyte. The mean peak area for quality control samples (at low and high QCs) was prepared in 50\% methanol and compared to the corresponding samples included extracted blank The matrix effect was expressed as a matrix factor (MF) and internal standard normalized matrix factor. The
MF and internal standard normalized factors were calculated by the following equations:

Internal standard normalized factor $=\frac{\text { Matrix factor of analyte }}{\text { Matrix factor of internal standard }}$

The coefficient of variation (CV) of the ISnormalized MF should not exceed $15 \%$.

\section{Accuracy and precision}

Intra-day precision and accuracy were evaluated by analyzing six replicates of each QC sample on the same day. The selected concentrations of QC samples were $10 \mathrm{ng} / \mathrm{mL}$ for DOX, CAM, and EN and CP (LLQC), $60 \mathrm{ng} / \mathrm{mL}$ (Low QC), $600 \mathrm{ng} / \mathrm{mL}$ (medium $\mathrm{QC}$ ), and $800 \mathrm{ng} / \mathrm{mL}$ (high QC). To evaluate the interday precision, the same quality control samples (freshly prepared) were analyzed together with one independent calibration reference curve on three different days. Intraday precision and inter-day precision were expressed as $\mathrm{CV}$. The acceptance criteria for intra-day and inter-day precision are up to $15 \%$ for low OQ, medium OQ, and high OQ samples and up to $20 \%$ for LLOQ samples.

\section{Extraction recovery}

The extraction recovery was performed to evaluate the loss of analytes and/or internal standards during sample extraction. The extraction recovery was observed in triplicate at three QC concentration levels (low QC, medium QC, and high QC). Both the extract of spiked samples of blank milk and references spiked to analyte free milk extract (post extract) were analyzed and the extraction recoveries were calculated based on the following equation:

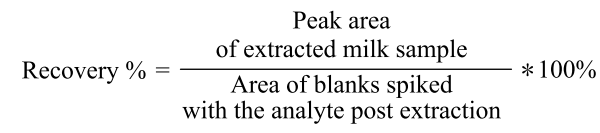

\section{RESULTS AND DISCUSSION}

\section{Mass spectrometric analysis}

The optimized MS parameters including precursor ion $(\mathrm{Q} 1)$, product ion $(\mathrm{Q} 3)$, declustering potential (DP), entrance potential (EP), collision energy (CE), and cell exit potential (CP) for all analates and internal standard are listed in Table 2.

Table 2. Optimized MS/MS parameters used in the validation of DOX, CAM, EN, and CP.

\begin{tabular}{|c|c|c|c|c|c|}
\hline Analyte & $\mathrm{Q} 1(\mathrm{~m} / \mathrm{z})$ & Q3 (m/z) & $\mathrm{DP}(\mathrm{V})$ & $\mathrm{EP}(\mathrm{V})$ & CXP (V) \\
\hline DOX & 445.074 & 427.500 & 50 & 7 & 25 \\
\hline CAM & 322.705 & 274.900 & 30 & 10 & 12 \\
\hline $\mathrm{EN}$ & 360.411 & 245.00 & 75 & 9 & 15 \\
\hline $\mathrm{CP}$ & 332.187 & 287.900 & 75 & 15 & 15 \\
\hline Etoricoxib (IS) & 359.000 & 280.000 & 70 & 10 & 12 \\
\hline
\end{tabular}


Intense and stable precursor and product ions were obtained for all analytes and internal standard (IS). In this study a single parent ion and single product ion were detected for each analyte. The parent ions (Q1 $[\mathrm{m} / \mathrm{z}]=445.1,360.4,332.2$, and 359.0 correspond with the protonated molecular ions $\left([\mathrm{M}+\mathrm{H}]^{+}\right)$of DOX, EN, $\mathrm{CP}$ and etoricoxib (IS) respectively, the product ions $(\mathrm{Q} 3[\mathrm{~m} / \mathrm{z}]=427.5)$ corresponds with the loss of ammonia from the protonated molecular ions $[\mathrm{M}+\mathrm{H}-17]^{+}$) of DOX. The product ion $(\mathrm{Q} 3[\mathrm{~m} / \mathrm{z}]=245.0)$ is associated with the loss of 1-Ethylpiperazine $\left(\mathrm{C}_{6} \mathrm{H}_{14} \mathrm{~N}_{2}\right)$ ring from the protonated molecular ion of EN. The product ions (Q3 [m/z] $=287.9$ and 280.0) correspond
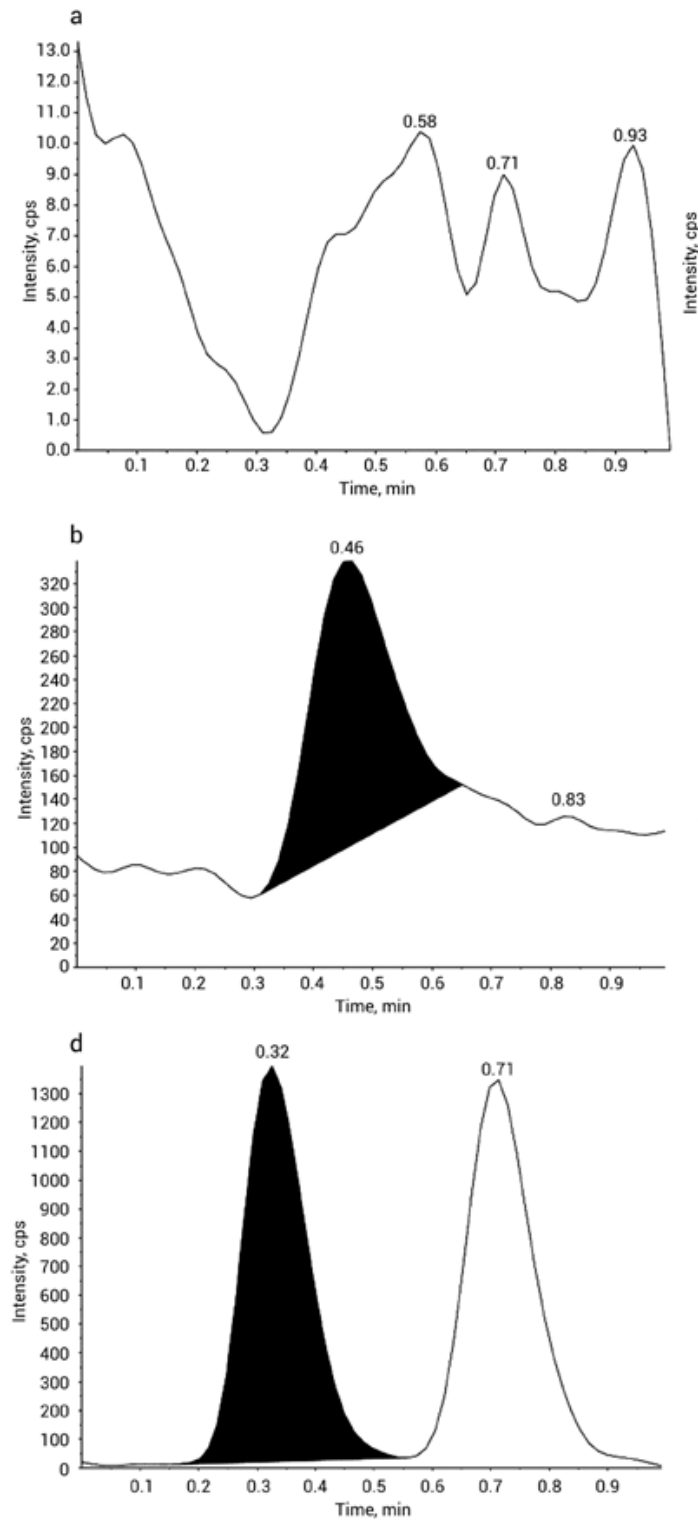

with the loss of $\mathrm{CO}_{2}$ from the protonated molecular ions $[\mathrm{M}+\mathrm{H}-44]^{+}$) of $\mathrm{CP}$ and the methyl sulfone group from protonated molecular ions $\left(\left[\mathrm{M}+\mathrm{H}-\mathrm{CH}_{3} \mathrm{SO}_{2}\right]^{+}\right)$of etoricoxib, respectively. Analyzing CAM by applying positive ionization mode led to the formation of the molecular ion at $\mathrm{m} / \mathrm{z} 322.7$ and a fragment ion at $\mathrm{m} / \mathrm{z}$ 274.9. Comparing fragments obtained from positive ionization of CAM with that reported from negative ionization, fragments were observed at $\mathrm{m} / \mathrm{z} 321$, 152,194 , and 257 when CAM was analyzed in the negative ionization mode.

Figure 2A represents MRM chromatograms for extracted drug-free milk samples with IS only. In this

Figure 2a. MRM chromatograms of spiked blank milk sample with IS only; Figure 2b. MRM chromatograms of spiked DOX at LLOQ concentration, $10 \mathrm{ng} / \mathrm{mL}$; Figure 2c. MRM chromatograms of spiked CAM at LLOQ concentration, $10 \mathrm{ng} / \mathrm{mL}$; Figure 2d. MRM chromatograms of spiked EN at LLOQ concentration, $10 \mathrm{ng} / \mathrm{mL}$; Figure 2e. MRM chromatograms of spiked CP at LLOQ concentration, $10 \mathrm{ng} / \mathrm{mL}$. 
chromatogram, the interfering peaks are almost absent at the retention times of DOX, CAM, EN, and CP. Figures $2 b, 2 c, 2 d$, and $2 \mathrm{e}$ are representative chromatograms for CAM, EN, and $\mathrm{CP}$, respectively, at the LLOQ level $(10 \mathrm{ng} / \mathrm{mL})$. The peak areas observed at the retention time of all analytes in Figure 2a were less than $20 \%$ of the LLOQ peak areas of EN, DOX, $\mathrm{CAM}$, and $\mathrm{CP}$ in the Figures from $2 \mathrm{~b}$ to $2 \mathrm{e}$.

\section{Linearity}

The analytical performance of this method is summarized in Table 3. The mean linear equations for calibration curves were $\mathrm{y}=0.00016 \mathrm{x}-0.00083$ for DOX, $\mathrm{y}=0.00018 \mathrm{x}+0.00040$ for CAM, $\mathrm{y}=0.00049 \mathrm{x}-0.00173$ for EN and $\mathrm{y}=0.00010 \mathrm{x}$ +0.00009 for CP. The studied concentration ranges were 10.0-1000 ng/mL for DOX, CAM, EN, and $\mathrm{CP}$. The correlation coefficients $\left(\mathrm{R}^{2}\right)$ were equal to or greater than 0.9972 for all analytes in the studied concentration ranges, and this confirms good linear relationships by the internal standard calibration curve. LLOQ values were in the range of $10 \mathrm{ng} / \mathrm{mL}$ for EN, DOX, CAM, and CP. All values of LLOQ were below the regulatory limits (MRLs) set by the European Commission.

\section{Matrix effect}

The matrix effect for DOX. CAM, EN, and CP in milk were studied by calculating the matrix factor (MF) and the internal standard-normalized matrix factor (IS-normalized MF). The results of the matrix effect are summarized in Table 4. No apparent matrix effect was observed for CAM, and $\mathrm{CP}$ (MF is higher than 0.85 ), while a slight ion suppression was observed for DOX in high QC samples $(\mathrm{MF}=0.84)$, and for EN in high and low QC samples $(\mathrm{MF}=0.83$ and 0.81$)$ respectively. The internal standard-normalized matrix factor was in the range of $0.90-1.11$; this confirms that the internal standard can correct the change in any potential matrix effect for DOX, CAM, EN, and CP. Maximum observed CV referred to a low level of QC samples of CP and was equivalent to $5.7 \%$. This data meets the acceptance criteria set by the European Medicines Agency (18, 19). Although milk is considered a complex matrix and contains a high content of protein and fat, our sample pretreatments are effective in reducing the matrix effect.

\section{Specificity and selectivity}

The presence of endogenous interfering peaks was investigated by analyzing the extracted blank milk samples from eight different sources and compared to samples spiked with DOX, CAM, EN, and $\mathrm{CP}$ at the lower limit of quantification (LLOQ; $10 \mathrm{ng}$ / $\mathrm{mL}$ for DOX, CAM, EN, and $\mathrm{CP}$ ). The interfering peak area should not exceed $20 \%$ of the peak area of the analyte and $5 \%$ of the peak area of the IS at the LLOQ $(18,19)$. Furthermore, to confirm the validity of the used blank, an antimicrobial activity screening test was conducted for long-life full-fat milk using seeded media with St. aureus gem + be bacterias, the

Table 3. Retention times (tRs), calibration curve equations, (R2), and LLOQs, for DOX, CAM, EN, and CP.

\begin{tabular}{|c|c|c|c|c|c|}
\hline Analyte & $\mathrm{t}_{\mathrm{R}}(\mathrm{min})$ & Linear equation & Linear range $(\mathrm{ng} / \mathrm{L})$ & $\mathrm{R}^{2}$ & LLOQ $(\mathrm{ng} / \mathrm{L})$ \\
\hline DOX & 0.52 & $\mathrm{Y}=0.00016 \mathrm{X}-0.00083$ & $10.000-1000.0$ & 0.9977 & 10 \\
\hline CAM & 0.43 & $\mathrm{Y}=0.00018 \mathrm{X}+0.00040$ & $10.000-1000.0$ & 0.9987 & 10 \\
\hline $\mathrm{EN}$ & 0.52 & $\mathrm{Y}=0.00049 \mathrm{X}-0.00173$ & $10.000-1000.0$ & 0.9987 & 10 \\
\hline $\mathrm{CP}$ & 0.52 & $\mathrm{Y}=0.00010 \mathrm{X}+0.00009$ & $10.000-1000.0$ & 0.9973 & 10 \\
\hline Etoricoxib (IS) & 0.71 & $2.0 \mu \mathrm{g} / \mathrm{mL}$ & - & - & - \\
\hline
\end{tabular}

Table 4. Matrix factor and internal standard normalized matrix factor.

\begin{tabular}{|c|c|c|c|c|}
\hline \multirow{2}{*}{ Analyte } & Concentration ng/mL & MF & IS-Normalized MF & CV (\%) \\
\hline \multirow{2}{*}{ DOX } & low & 0.869 & 0.912 & 3.31 \\
\cline { 2 - 5 } & high & 0.839 & 0.902 & 3.24 \\
\hline \multirow{2}{*}{ CAM } & low & 0.902 & 0.912 & 3.86 \\
\cline { 2 - 5 } & high & 0.890 & 1.110 & 4.69 \\
\cline { 2 - 5 } EN & low & 0.830 & 0.910 & 4.20 \\
\hline \multirow{2}{*}{ CP } & high & 0.810 & 0.900 & 5.74 \\
\cline { 2 - 5 } & low & 0.948 & 1.098 & 4.08 \\
\hline
\end{tabular}


seeded media inoculated with the milk as a sample and purified water as blank (- be control). After incubation overnight good growth of bacterial appears with no sign of inhibition zone of growth around the milk sample or the -be control.

\section{Accuracy and precision}

The accuracy and precision (within-day and between-day) were estimated by analyzing the spiked blank samples of milk at four concentration levels, LLOQ (10 ng/mL for CAM, DOX, EN; $10 \mathrm{ng} / \mathrm{mL}$ for $\mathrm{CP})$, low QC (60 ng/mL), medium QC (400 ng/mL), and High QC (800 ng/mL). In accordance with the Commission Decision 2002/657/CE of the EU, accepted accuracies are extended from $85 \%-110 \%$. The maximum acceptable variance coefficient (CV) should not be more than $15 \%$ for analyte concentration at low QC, medium QC and high QC or $20 \%$ for analyte concentration at LLOQ As shown in Table 5, data showed accuracies were ranged from $92.48 \%$ to $110.05 \%$ and the relative error of accuracy did not exceed $20 \%$. The CV values of both inter-day and intra-day were below $12.66 \%$ and $11.76 \%$, respectively. These results revealed that the validated method has good precision and accuracy and is convenient for daily routine analysis.

\section{Extraction recovery}

Extraction recoveries are listed in Table 6. The mean recoveries were $88.70 \%$ for CAM and $61.67 \%$ for EN. This data confirms that the extraction method that has been used is stable and efficient for CAM and EN. On the other hand, the extraction recoveries were reported as $4.50 \%$ for CP and $10.02 \%$ for DOX. The extraction recovery of IS at $2.0 \mu \mathrm{g} / \mathrm{mL}$ was estimated to be $61.57 \% \pm 7.72$. In spite of low recovery for $\mathrm{CP}$, it was accepted based on the guideline's acceptance criteria.

\section{Application of the method to quantify DOX, CAM, EN, and CP in milk samples}

The proposed method was applied to determine DOX, CAM, EN, and CP in 26 milk samples (14 samples of long-term milk, 9 samples of powdered milk,

Table 5. Accuracy (\%) with relative standard deviation, within- and between-day precision values for quality control samples.

\begin{tabular}{|c|c|c|c|c|}
\hline \multicolumn{5}{|c|}{ Within run accuracy (\%) and R.S.D } \\
\hline \multicolumn{5}{|c|}{ Concentration } \\
\hline Analyte & $10 \mathrm{ng} / \mathrm{mL}$ & $60 \mathrm{ng} / \mathrm{mL}$ & $400 \mathrm{ng} / \mathrm{mL}$ & $800 \mathrm{ng} / \mathrm{mL}$ \\
\hline DOX & $104.57 \pm 13.41$ & $100.21 \pm 11.33$ & $96.59 \pm 9.80$ & $109.36 \pm 7.93$ \\
\hline CAM & $94.91 \pm 9.43$ & $100.11 \pm 4.89$ & $98.26 \pm 2.94$ & $99.32 \pm 11.47$ \\
\hline EN & $110.05 \pm 4.05$ & $105.12 \pm 8.72$ & $98.65 \pm 8.46$ & $108.56 \pm 8.36$ \\
\hline CP & $92.48 \pm 19.48$ & $100.19 \pm 4.50$ & $101.62 \pm 6.19$ & $98.80 \pm 2.58$ \\
\hline \multicolumn{5}{|c|}{ Within-day precision $(\mathrm{CV} \%)$} \\
\hline DOX & 9.68 & 2.60 & 5.43 & 12.71 \\
\hline CAM & 10.09 & 11.76 & 12.71 & 10.09 \\
\hline EN & 10.09 & 11.76 & 12.28 & 10.09 \\
\hline CP & 19.67 & 3.03 & 4.78 \\
\hline & & Between-day precision (CV\%) & \\
\hline DOX & 12.09 & 9.68 & 11.78 & 11.52 \\
\hline CAM & 11.89 & 10.08 & 12.66 & 5.11 \\
\hline EN & 12.60 & 8.52 & 2.81 & 7.75 \\
\hline CP & 10.09 & 3.63 &
\end{tabular}

Table 6. Extraction recoveries with Relative Standard Deviation (RSD) for DOX, CAM, EN, and CP.

\begin{tabular}{|c|c|c|c|c|c|}
\hline Analyte & $60 \mathrm{ng} / \mathrm{mL}$ & $400 \mathrm{ng} / \mathrm{mL}$ & $800 \mathrm{ng} / \mathrm{mL}$ & Mean recovery $(\%)$ & CV (\%) \\
\hline DOX & 11.35 & 9.14 & 9.56 & 10.02 & 11.72 \\
\hline CAM & 71.89 & 86.38 & 107.83 & 88.70 & 20.39 \\
\hline EN & 59.48 & 55.28 & 70.25 & 61.67 & 12.52 \\
\hline CP & 4.15 & 4.80 & 4.54 & 4.50 & 7.27 \\
\hline
\end{tabular}


and 3 samples of untreated raw milk samples). First, non-targeted screening was performed from the obtained samples of green cow's farm (which already confirmed by antibacterial activity test) to find samples that may contain one or more of the analytes (DOX, CAM, EN, and CP) in the absence of the IS. Then, IS was applied to validate and quantify the analytes. In this study, out of the total 26 samples of milk, ciprofloxacin was detected in only two samples of untreated raw milk (2.5\%). Ciprofloxacin was detected at a trace level (below LLOQ (BLLOQ), 8.75 and $9.77 \mathrm{ng} / \mathrm{L}$ ). Although the extraction recovery of CP suffers from limitation, an adequate response to $\mathrm{CP}$ was observed. Concentrations of the detected antibiotic residues are summarized in Table 7.

All selected cow's milk samples including their natural fat contents, to avoid pre-extraction for targeted analytes. Such current findings are in agreement with the previous studies of similar objectives that found a small percentage of antibiotic residues with many cow's milk samples of different brands $(12,20)$.

\section{CONCLUSION}

This research is establishing a suitable method of analysis that can be used as a simple method for the detection of some antibiotic residues, especially these antibiotics widely used for the prevention and treatment of disease in milk-producing animals. This validated LC-MS /MS method proposes a fast and high throughput method for simultaneous quantification of four antibiotics (DOX, CAM, EN, and CP) in milk samples that have been obtained from the Jordanian market. The developed extraction method and sample pretreatment were simple, low cost, and easy to use. The LLOQ was also much lower than the maximum residue limit. Moreover, this method

Table 7.Concentrations in $\mathrm{ng} / \mathrm{mL}$ found in milk samples.

\begin{tabular}{|c|c|c|c|c|c|c|}
\hline $\begin{array}{l}\text { Sample tested (Milk } \\
\text { Code number) }\end{array}$ & Milk sample form & DOX & CAM & $\mathrm{EN}$ & $\mathrm{CP}$ & Comment \\
\hline 01 & Long term liquid & Negative & Negative & Negative & Negative & BLLOQ \\
\hline 02 & Long term liquid & Negative & Negative & Negative & Negative & BLLOQ \\
\hline 03 & Long term liquid & Negative & Negative & Negative & Negative & BLLOQ \\
\hline 04 & Long term liquid & Negative & Negative & Negative & Negative & BLLOQ \\
\hline 05 & Long term liquid & Negative & Negative & Negative & Negative & BLLOQ \\
\hline 06 & Long term liquid & Negative & Negative & Negative & Negative & BLLOQ \\
\hline 07 & Long term liquid & Negative & Negative & Negative & Negative & BLLOQ \\
\hline 08 & Long term liquid & Negative & Negative & Negative & Negative & BLLOQ \\
\hline 09 & Long term liquid & Negative & Negative & Negative & Negative & BLLOQ \\
\hline 10 & Long term liquid & Negative & Negative & Negative & Negative & BLLOQ \\
\hline 11 & Long term liquid & Negative & Negative & Negative & Negative & BLLOQ \\
\hline 12 & Long term liquid & Negative & Negative & Negative & Negative & BLLOQ \\
\hline 13 & Long term liquid & Negative & Negative & Negative & Negative & BLLOQ \\
\hline 14 & Long term liquid & Negative & Negative & Negative & Negative & BLLOQ \\
\hline 15 & Powdered & Negative & Negative & Negative & Negative & BLLOQ \\
\hline 16 & Powdered & Negative & Negative & Negative & Negative & BLLOQ \\
\hline 17 & Powdered & Negative & Negative & Negative & Negative & BLLOQ \\
\hline 18 & Powdered & Negative & Negative & Negative & Negative & BLLOQ \\
\hline 19 & Powdered & Negative & Negative & Negative & Negative & BLLOQ \\
\hline 20 & Powdered & Negative & Negative & Negative & Negative & BLLOQ \\
\hline 21 & Powdered & Negative & Negative & Negative & Negative & BLLOQ \\
\hline 22 & Powdered & Negative & Negative & Negative & Negative & BLLOQ \\
\hline 23 & Powdered & Negative & Negative & Negative & Negative & BLLOQ \\
\hline 24 & Raw untreated & Negative & Negative & Negative & Negative & 8.75 \\
\hline 25 & Raw untreated & Negative & Negative & Negative & Negative & 9.78 \\
\hline 26 & Raw untreated & Negative & Negative & Negative & Negative & BLLOQ \\
\hline
\end{tabular}


shows good linearity, high accuracy, and high precision which can be used for QC analysis of the residues of the above-mentioned products.

Development of the method of analysis using $\mathrm{LC} / \mathrm{MS}$ for some antibiotics residues in milk in the Jordan market is very important for the safety of consumer health and at the same time to remove or reject the contaminated milk product from the marketplace.

\section{Acknowledgment}

The authors wish to thank the Deanship of Scientific Research at Al-Ahliyya Amman University, Amman, Jordan for their financial support and funding. Additionally, the authors acknowledge the technical support of the Jordan Center for Pharmaceutical Research, Amman, Jordan, and Mohamad Rafiq and Munzer Molhem for their contribution during the analysis of the samples.

\section{Conflicts of interest}

The authors declare no conflict of interest.

\section{REFERENCES}

1. Hoelzer K., Wong N., Thomas J., Talkington K., Jungman E., Coukell A.: BMC Vet. Res. 13, 211 (2017).

2. Phares C.A., Danquah A., Atiah K., Agyei F.K., Michae O.T.: PLoS One 15, e0228777 (2020).

3. McGee E.U., Samuel E., Boronea B., Dillard N., Milby M.N., Lewis S.J.: Pharmacy (Basel) 7, 97 (2019).

4. Fair R.J., Tor Y.: Perspect. Medicin. Chem. 6, 25 (2014).

5. Becattini S., Taur Y., Pamer E.G.: Trends Mol. Med. 22, 458 (2016).

6. Commission Regulation, Commission Regulation (EU) No 37/2010 of 22 December 2009 on pharmacologically active substances and their classification regarding maximum residue limits in foodstuffs of animal origin, Off. J. Eur. Union. (2010).

7. E.L.- Residues, 2009/470/EC residue limits, Regul. NO. 470/2009 Eur. Parliam. Counc.
6 May 2009 Lay. down Community Proced. Establ. Residue Limits Pharmacol. Act. Subst. Foodst. Anim. Orig. Repealing Counc. Regu. (2009).

8. C. Minister of Justice, Safe Food for Canadians Act Loi sur la salubrité des aliments au Canada, (2015). http://www.inspection.gc.ca/food/meatand-poultry-products/manual-of-procedures/ chapter-5/eng/1395150894222/1395150895519? chap $=2$.

9. Swartenbroux, Hoffmann A., Commission staff working document on the implementation of national residue monitoring plans in the member states in 2009, 2009 (2010).

10. Dalhoff A.: Eur. J. Clin. Microbiol. Infect. Dis. 34, 661 (2015).

11. Nicolaou K.C., Rigol S.: J Antibiot. (Tokyo) 71, 153 (2018).

12. Aguilera-Luiz M.M., Vidal J.L.M., RomeroGonzález R., Frenich A.G.: J. Chromatogr. A. 1205, 10 (2008).

13. Freitas A., Barbosa J., Ramos F.: Int. Dairy J. 33, 38 (2013).

14. Jank L., Martins M.T., Arsand J.B., Campos Motta T.M., Hoff R.B., et al.: Talanta 144, 686 (2015).

15. Verdon E., Couedor P., Roudaut B., Sanders P.: J. AOAC Int. 88, 1179 (2005).

16. Sachi S., Ferdous J., Sikder M.H., Azizul Karim Hussani S.M.: J. Adv. Vet. Anim. Res. 6, 315 (2019).

17. Gaugain-Juhel M., Delépine B., Gautier S., Fourmond M.P., Gaudin V., et al.: Food Addit. Contam. Part A Chem. Anal. Control Expo. Risk Assess. 26, 1459 (2009).

18. Ema, Guideline on bioanalytical method validation, EMEA, Comm. Med. Prod. Hum. Use. 44, pp. 1-23 (2012).

19. H. Services, Analytical Procedures and Methods Validation for Drugs and Biologics Guidance for Industry Analytical Procedures and Methods Validation for Drugs and Biologics Guidance for Industry, (2015).

20. Bion C., Henzelin A.B., Qu Y., Pizzocri G., Bolzoni G., Buffoli E.: Food Addit. Contam. Part A Chem. Anal. Control Expo. Risk Assess. 33, 54 (2015). 